\title{
Higher Postinduction Infliximab Serum Trough Levels Are Associated With Healing of Fistulizing Perianal Crohn's Disease in Children
}

\author{
Wael El-Matary, MD, MSc, ${ }^{*}$ Thomas D. Walters, MD, ${ }^{+}$Hien Q. Huynh, MD, ${ }^{\ddagger}$ Jennifer deBruyn, $M D^{\S}{ }^{\S}$ \\ David R. Mack, MD," Kevan Jacobson, MD," Mary E. Sherlock, MD, ${ }^{* *}$ Peter Church, MD, ${ }^{+}$ \\ Eytan Wine, MD, PhD, ${ }^{\ddagger}$ Matthew W. Carroll, MD, Eric l. Benchimol, MD, PhD, ${ }^{\mathbb{1}, t+}$ \\ Sally Lawrence, $M D^{\prime \prime}$ and Anne M. Griffiths, $M D^{+}$
}

\begin{abstract}
Background: There is some evidence in adults that higher serum infliximab (IFX) levels are needed to adequately treat fistulizing perianal Crohn's disease (CD). However, data in children are lacking. We aimed to determine postinduction serum trough IFX levels that are associated with healing of fistulizing perianal CD (PCD) at week 24.

Methods: In a multicenter inception cohort study, consecutive children younger than age 17 years with fistulizing perianal CD treated with IFX between April 2014 and June 2017 who had serum trough IFX titers measured before the fourth infusion were included. Area under the receiver operating characteristic curve (AUROC) was calculated to determine the best cutoff to predict fistula healing.

Results: A total of 667 children with Crohn's disease were recruited, with 85 (12.7\%) patients diagnosed with fistulizing PCD. There were 27 of $52(52 \%)$ children in whom pre-fourth infusion IFX levels were measured (mean age, $12.57 \pm 5.12$ years). At week 24,14 of 27 (52\%) patients responded with healing/healed PCD, whereas the rest had ongoing active fistulizing disease. The median IFX pre-fourth dose level in the responders was $12.7 \mathrm{ug} / \mathrm{mL}$, compared with $5.4 \mathrm{ug} / \mathrm{mL}$ in the active disease group $(P=0.02)$. There was a strong correlation between IFX levels and healing of fistulizing PCD at week $24(r=0.65 ; P<0.001)$. The AUROC was $0.80(95 \%$ confidence interval, $0.64-0.97 ; P=0.007)$ for pre-fourth IFX level to predict response of fistulizing PCD at week 24, and a level of $12.7 \mathrm{ug} / \mathrm{mL}$ best predicted fistula healing.
\end{abstract}

Conclusions: Higher trough IFX levels are associated with healing of fistulizing perianal CD.

Key Words: children, colitis, Crohn, fistula, infliximab

Received for publications February 24, 2018; Editorial Decision May 14, 2018.

From the *Section of Gastroenterology, Hepatology and Nutrition, Department of Pediatrics, Max Rady College of Medicine, University of Manitoba, Winnipeg, MB, Canada; 'Division of Gastroenterology, Hepatology and Nutrition, Department of Pediatrics, Hospital for Sick Children, Toronto, ON, Canada; ${ }^{\star}$ Department of Pediatrics, University of Alberta, Edmonton, AB, Canada; ${ }^{\S}$ Division of Pediatric Gastroenterology, Department of Pediatrics, Faculty of Medicine, University of Calgary, Alberta Children's Hospital, Calgary, AB, Canada; 'Children's Hospital of Eastern Ontario IBD Centre, Department of Pediatrics, University of Ottawa, Ottawa, ON, Canada; 'Division of Gastroenterology, B.C. Children's Hospital, Vancouver, BC, Canada; **Division of Gastroenterology and Nutrition, McMaster Children's Hospital, Hamilton Health Sciences, Hamilton, ON, Canada; ${ }^{\dagger \dagger}$ School of Epidemiology and Public Health, University of Ottawa, Ottawa, ON, Canada

Conflicts of interest: Wael El-Matary received research support from Janssen Canada and served as an advisory board member for Janssen Canada and AbbVie Canada.

Supported by: The Canadian Children Inflammatory Bowel Disease Network is supported by a grant from Canadian Institute of Health Research and the C.H.I.L.D Foundation.

Address correspondence to: Wael El-Matary MD, MSc, FRCPCH, FRCPC, Section of Pediatric Gastroenterology Hepatology and Nutrition, Department of Pediatrics, Rady Faculty of Health Sciences, University of Manitoba, AE 408, Health Sciences Centre, 840 Sherbrook St., Winnipeg, Manitoba R3A 1S1, Canada (welmatary@hsc.mb.ca).

(C) 2018 Crohn's \& Colitis Foundation. Published by Oxford University Press. All rights reserved. For permissions, please e-mail: journals.permissions@oup.com.

doi: 10.1093/ibd/izy217 Published online 15 June 2018

\section{INTRODUCTION}

Perianal Crohn's disease (PCD), usually disabling and aggressive, is defined as inflammation at or near the anus, including skin tags, fissures, fistulas, abscesses, or stenosis. The symptoms of PCD include pain, itching, bleeding, purulent discharge, and stool incontinence. ${ }^{1}$ The incidence of PCD in the pediatric age group has been estimated to be between 13\% and $62 \%{ }^{2-4}$ The majority of children with PCD have skin tags and fissures., ${ }^{2}$ The designation "perianal fistulizing disease," in contrast, as per Paris phenotypic classification of pediatric inflammatory bowel disease (IBD), denotes only patients with perianal fistulas or abscesses and excludes other perianal lesions. ${ }^{5}$ Clinically recognizable fistulas can occur in about $15 \%$ of children with PCD. ${ }^{3,6}$ Simple fistulizing disease is superficial and confined to the anal canal. In contrast, rectovaginal and complex fistulas rarely heal without therapy. Complex fistulas include those with origin of the fistulous tract that are high intersphincteric, high transsphincteric, extrasphincteric, or suprasphincteric. ${ }^{7}$

Treatment of PCD can be challenging, and was especially so before the biologic era. Even with a combined medical/surgical approach, sustained closure of perianal fistulas is difficult to achieve, and resolution is exceedingly slow. ${ }^{8}$ 
Anti-tumor necrosis factor (TNF) agents, particularly infliximab (IFX), constitute optimal firstline therapy for significant perianal fistulizing disease. Several studies have confirmed the efficacy of IFX in children and adults with PCD with a variable response rate from $36 \%$ to $73 \%$ at 54 weeks of maintenance therapy. ${ }^{9-13}$ Of note, the primary end point in all trials has been fistula response rather than remission, indicative of the challenge of attaining complete resolution.

Lack of response of fistulizing PCD to IFX might be related to several factors, one of which is suboptimal IFX serum levels. Reactive optimization of serum IFX levels through therapeutic drug monitoring (TDM) in adult patients with active Crohn's disease has been recommended. ${ }^{14}$

Recent retrospective analyses of outcomes in adult patients treated with IFX for fistulizing PCD have suggested that the serum levels of IFX required to achieve healing of PCD are higher than those generally accepted in the management of luminal inflammatory Crohn's disease (CD) $)^{15,16}$; however, such evidence does not exist in children. In a prospective multicenter inception cohort of newly diagnosed children with $\mathrm{CD}$, we aimed to assess the clinical response of perianal fistulas to infliximab therapy and examine the correlation of response with drug exposure.

\section{METHODS}

\section{Study Design and Patient Selection}

The Canadian Children Inflammatory Bowel Disease Network, a joint partnership of the CIHR and C.H.I.L.D Foundation (CIDsCaNN), includes 12 academic pediatric IBD centers across Canada. Since April 2014, children and adolescents aged $<17$ years with newly diagnosed IBD have been prospectively enrolled in an inception cohort study. Baseline and longitudinal phenotypic data are prospectively collected using standardized forms, which include a "perianal disease report form," and entered into a Research Electronic Data Capture (REDCap) database. Treatments are administered at the discretion of treating physicians. Children enrolled in the inception cohort who developed fistulizing perianal $\mathrm{CD}$ identified via clinical and/or magnetic resonance pelvic examination and who were treated with IFX between April 2014 and June 2017 were included in this study. Patients who did not have fistulizing perianal $\mathrm{CD}$ and those with fistulizing perianal $\mathrm{CD}$ but not treated with IFX were excluded.

\section{Description of Variables}

Data collected at baseline included patient demographics and disease phenotypic characteristics at diagnosis, including age, sex, ethnic background, family history of IBD, disease phenotype, clinical symptoms at diagnosis, Pediatric Crohn's Disease Activity Index (PCDAI) scores, anthropometric measures (weight, height, and body mass index $\mathrm{Z}$ scores), perianal clinical findings, and treatments administered. Data concerning dose and intervals of IFX were documented. Laboratory markers, including hemoglobin, serum albumin, erythrocyte sedimentation rate (ESR), and C-reactive protein (CRP), were performed by the local site laboratory and recorded in CIDsCaNN's standardized reporting form, with local values defining normal or abnormal results.

\section{Outcome Definitions}

Active fistulizing perianal $\mathrm{CD}$ was defined as the presence of at least 1 fistulous draining opening in the perianal area, as clinically identified by physical examination and/or magnetic resonance image of the pelvis. A healing perianal fistula was defined as decrease or cessation of fistula drainage, as reported by patients and confirmed by treating physicians. A healed fistula was defined as closure of a previously identified fistula opening, as reported by treating physicians. Patients were classified as responsive to treatment if their perianal fistulas were classified by the treating physicians as healing/healed. Clinical assessment for healing of fistulizing perianal $\mathrm{CD}$ was performed 24 weeks after starting IFX.

\section{IFX Serum Level Measurements}

Therapeutic drug monitoring with IFX therapy is facilitated as part of clinical care in Canada by Janssen Canada. During the time period of this study, up to 3 IFX trough level measurements per calendar year per pediatric patient were made available. Serum IFX trough titer was recommended to be performed routinely before the fourth dose for all CIDsCaNN patients. Measurements of IFX serum levels were performed through Dynacare Laboratories (Brampton, ON, Canada) using a commercial enzyme-linked immunosorbent assay (ELISA).

\section{Statistical Analysis}

Calculations and data analyses were performed using IBM SPSS, version 24.0 (IBM Corporation, Armonk, NY, USA) and the R Foundation for Statistical Computing, version 3.3.2 (R Foundation, Vienna, Austria). Summary measures (means, medians, interquartile ranges [IQRs], and standard deviations [SDs]) were calculated for continuous variables, whereas frequencies were calculated for categorical variables. The Wilcoxon signed-rank test was used to compare means. Binary logistic regression was applied to determine factors associated with perianal disease status, which was categorized as active and healed/healing state. All reported $P$ values were 2 -sided, and a $P$ value with a $5 \%$ level of significance was applied. For the calculation of casual relationship between categorical and continuous variables, 1-way analysis of variance was used. We used healing status as a binary variable ( 0 or 1); then we used generalized linear regression function to fit logistic regression between healing status and IFX levels. After 
TABLE 1: Demographic and Disease Characteristics at Infliximab Start in Patients With Clinically Evident Fistulizing Perianal Crohn's Disease and IFX Levels Measured vs Those Without IFX Levels Measured

\begin{tabular}{lcc}
\hline & $\begin{array}{c}\text { Patients With } \\
\text { IFX Levels }\end{array}$ & $\begin{array}{c}\text { Patients Without } \\
\text { IFX Levels }\end{array}$ \\
\hline No. (\%) & $27(52)$ & $25(48)$ \\
Mean age (SD), y & $12.5(5.1)$ & $13.2(4.3)$ \\
Sex & & \\
Male & $17(63)$ & $14(56)$ \\
Female & $10(37)$ & $11(44)$ \\
Location & & \\
L1 & & 2 \\
L2 & 3 & 9 \\
L3 & 8 & 13 \\
L4 & 14 & 5 \\
Concomitant medications & & \\
5-ASA & 5 & 3 \\
Azathioprine & & 8 \\
Methotrexate & 4 & 16 \\
Steroids & 9 & 7 \\
Enteral nutrition & 14 & \\
Antibiotics (metronidazole & 21 & \\
and/or ciprofloxacin) & 3 & \\
Concomitant surgical interven- & $7(26)$ & \\
tion (abscess drainage with or & & \\
without seton placement) & & \\
\hline
\end{tabular}

a Patients may have more than 1 location.

bPatients may have more than 1 medication.

fitting the model, we produced the predicted value of Y, which is status. For correlation, Pearson's correlation test was used.

Univariable analysis was applied on covariables. The results of univariable logistic regression (with the dependent variable as healing/healed fistula) were presented as odds ratios (ORs) with 95\% confidence intervals (CIs). Area under the receiver operating characteristic curve (AUROC) was determined for the evaluation of the accuracy of the prediction of fistula response to serum IFX levels.

\section{Ethical Considerations}

The study protocol was approved by the research ethics boards of all collaborating centers.

\section{RESULTS}

A total of 667 children (mean age at diagnosis, $13.3 \pm 3.3$ years; $406[60.8 \%]$ male) with CD were enrolled during the 3 -year period in the national inception cohort study. Fistulizing perianal CD was present in $85(12.7 \%)$ patients (mean age, $13.5 \pm 3.4$ years; 56 [65.8\%] male), with fistulas identified clinically in $70(82.4 \%)$, and via magenetic resonance of the pelvis in only $15(17.6 \%)$. Of the 70 patients with clinically evident fistulizing PCD, $52(74.3 \%)$ received IFX therapy. Twenty-seven (mean age, $12.5 \pm 5.1$ years; $63 \%$ males) of 52 $(52 \%)$ children with fistulizing perianal CD on IFX had serum IFX pre-fourth dose trough level measurement.

The demographic disease characteristics of those patients and details of concomitant medications and perianal surgery are summarized in Table 1. There were no significant differences between those with and without measurement of serum trough levels in clinical disease activity scores or laboratory markers at the time of IFX introduction (Table 2).

All patients received a conventional 3-dose induction regimen $(5 \mathrm{mg} / \mathrm{kg} / \mathrm{dose}$, often rounded up to the nearest $100 \mathrm{mg}$ at weeks 0, 2, 6; median [IQR], 6 [5.8-7.8] mg/kg). Dose 4 was received at a median time interval following the third dose (IQR) of 50 (42-57) days. At week 24, 14 of 27 (52\%) patients were classified as responders with clinically healing/healed perianal CD whereas the rest had ongoing active fistulizing perianal CD. The demographic disease characteristics of those patients are summarized in Table 3. The median serum IFX pre-fourth dose trough level in responsive fistulae (IQR) was 12.7 (6.615.5) $\mu \mathrm{g} / \mathrm{mL}$ compared with $5.4(2.7-8.4) \mu \mathrm{g} / \mathrm{mL}$ in the nonresponsive perianal CD disease group $(P=0.02)$ (Fig. 1).

There was a significant correlation between serum IFX levels before the fourth dose and healing of fistulizing perianal $\mathrm{CD}$ at week $24(r=0.65 ; P=0.0002)$.

TABLE 2: Disease Activity and Laboratory Markers at Infliximab Start in Patients With Clinically Evident Fistulizing Perianal Crohn's Disease and Infliximab Levels Compared With Those Without Levels Measured

\begin{tabular}{lcr}
\hline Disease Activity and Laboratory Markers & Patients With IFX Levels & Patients Without IFX Levels \\
\hline PCDAI, mean (SD) & $61.30 \pm 30.67$ & $61.25 \pm 36.38$ \\
ESR, mean (SD), mm/h & $46.13 \pm 27.47$ & $48.7 \pm 30.07$ \\
Hemoglobin, mean (SD), g/L & $109.91 \pm 14.24$ & $112.92 \pm 18.15$ \\
CRP, mean (SD), mg/L & $62.64 \pm 58.90$ & $57.88 \pm 70.33$ \\
Albumin, mean (SD), g/L & $32.75 \pm 6.60$ & $35.18 \pm 6.80$ \\
\hline
\end{tabular}


TABLE 3: Baseline Demographic, Disease, and Laboratory Characteristics of IFX Responders vs Nonresponders at Week 24

\begin{tabular}{lcc}
\hline & $\begin{array}{r}\text { Active Perianal } \\
\text { Disease }(\mathrm{n}=13)\end{array}$ & $\begin{array}{c}\text { Healing/Healed Fistula } \\
(\mathrm{n}=14)\end{array}$ \\
\hline Mean age (SD), y & $12.29(2.24)$ & $12.63(3.97)$ \\
Male sex, No. (\%) & $8(61.50)$ & $9(64.30)$ \\
Linear growth impairment, No. $(\%)$ & $11(78.60)$ \\
Yes & $11(84.60)$ & $3(21.40)$ \\
No & $2(15.40)$ & $61.96(31.53), P=0.45$ \\
Disease activity (SD) & $56.35(28.41)$ & $105.0(14.49), P=0.32$ \\
Hemoglobin (SD), g/L & $111.20(15.59)$ & $59.61(56.62), P=0.01$ \\
CRP (SD), mg/dL & $48.76(27.19)$ & $29.86(7.20), P=0.28$ \\
Albumin (SD), g/L & $33.85(6.22)$ & $2(14.3)$ \\
Location of Crohn's disease, ${ }^{\mathrm{a}}$ No. $(\%)$ & $3(21.4)$ \\
L1 +/- L4 & $1(7.7)$ & $8(61.5)$ \\
L2 +/- L4 & $5(38.5)$ & \\
L3 +/- L4 & $6(46.1)$ & \\
\hline
\end{tabular}

aPatients may have more than 1 location.

In a univariable regression analysis (Table 4), age, sex, and laboratory markers were not associated with fistula response at week 24; however, serum IFX pre-fourth dose trough levels were significantly associated with fistula response at week 24 (OR, 1.2; 95\% CI, 1.004-1.29; $P=0.04$ ).

The AUROC for serum IFX pre-fourth dose trough levels to predict response of fistulizing perianal CD at week 24 was 0.80 (95\% CI, 0.64-0.97; $P=0.007)$, and a level of $12.7 \mu \mathrm{g} / \mathrm{mL}$ predicted fistula healing at week 24 with a sensitivity of 0.62 and specificity of 0.65 (Fig. 2).

\section{DISCUSSION}

Infliximab is an effective treatment of fistulizing perianal CD. ${ }^{15,16}$ In our study, more than $50 \%$ of children with fistulizing PCD had clinical response 24 weeks after starting IFX therapy. We demonstrated a correlation between IFX exposure, as reflected by trough levels at the start of maintenance therapy, and subsequent healing of fistulizing perianal CD in children.

Our results are consistent with those of recent adult studies. In a cross-sectional study, Yarur et al. demonstrated that adult patients with healed perianal fistulas had significantly higher median IFX trough levels $(15.8 \mu \mathrm{g} / \mathrm{mL})$ compared with those with active fistulizing PCD $(4.4 \mu \mathrm{g} / \mathrm{mL}) .{ }^{15}$ In that study, 63 of 117 patients $(53.9 \%)$ achieved perianal fistula healing. In addition, there was an incremental gain in fistula healing with higher IFX levels. In receiver operating characteristic (ROC) curve analysis, there was a strong association of serum IFX levels and fistula healing, with an AUROC of $0.82(P<0.0001) .{ }^{15}$

Similarly, Davidov et al. demonstrated that higher serum IFX trough levels at weeks 2 and 6 were associated with higher rates of healing at weeks 14 and 30 in 36 adults with fistulizing perianal CD. ${ }^{16}$ The area under the curve (AUC) for association of IFX level at week 2 with fistula improvement at week 14 was $0.94(P=0.0001) .{ }^{16}$ A serum IFX level of $9.25 \mu \mathrm{g} / \mathrm{mL}$ was predictive of fistula response at week 14 , with a sensitivity of $89 \%$ and a specificity of $90 \%$. The AUROC for association of IFX level at week 6 with fistula improvement at week 14 was $0.90(P=0.001)$. An IFX trough titer of $7.25 \mu \mathrm{g} / \mathrm{mL}$ at week 6 was associated with fistula improvement at week 14, with a sensitivity of $80 \%$ and a specificity of $83 \%$. At week 30 , fistula response occurred in 23 of 36 patients $(63.9 \%) .{ }^{16}$

In luminal $\mathrm{CD}$, anti-TNF drug concentrations during and early after induction therapy are associated with favorable therapeutic outcomes in IBD. ${ }^{17-21}$ This suggests that early optimization of anti-TNF therapy may prevent some primary nonresponse and lead to better short- and long-term outcomes. ${ }^{17}$

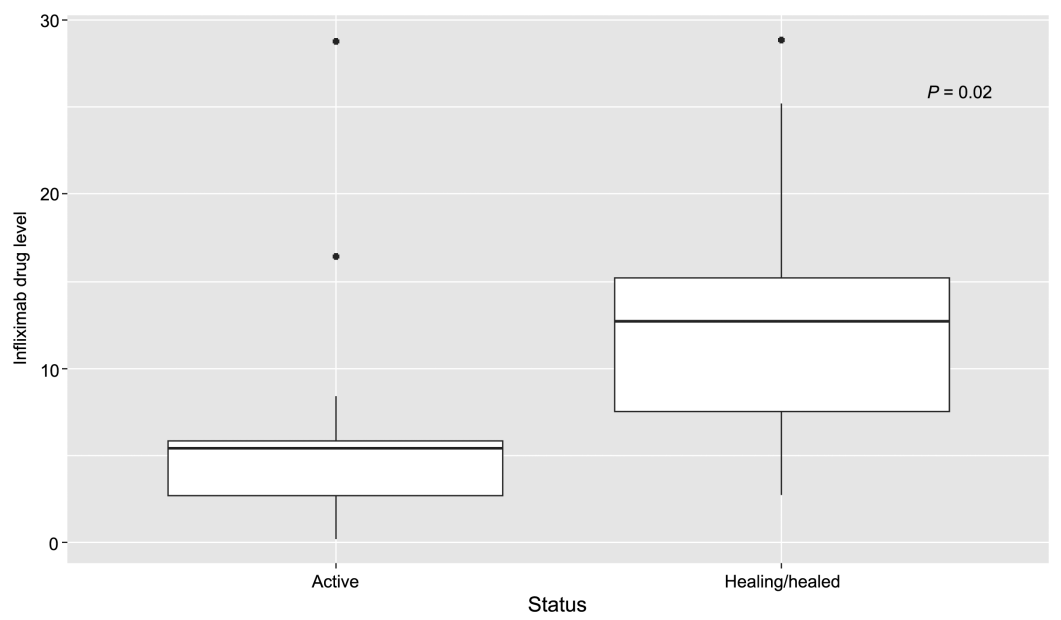

FIGURE 1. Serum IFX pre-fourth dose trough levels $(\mu \mathrm{g} / \mathrm{mL})$ in children with nonresponsive perianal CD vs those with response (healing/healed perianal fistula). 
TABLE 4: Factors Examined as Potential Predictors of Fistula Healing 24 Weeks After Starting Infliximab

\begin{tabular}{lcc}
\hline Variable & OR $(95 \% \mathrm{CI})$ & $P$ \\
\hline Age & $1.10(0.98-1.03)$ & 0.78 \\
Female sex & $0.889(0.18-4.34)$ & 0.88 \\
Infliximab levels & $1.20(1.004-1.30)$ & $\mathbf{0 . 0 4}$ \\
Linear growth impairment $(\mathrm{G} 1)^{\mathrm{a}}$ & $1.50(0.21-13.15)$ & 0.69 \\
Albumin & $0.91(0.79-1.03)$ & 0.14 \\
Disease activity & $1.10(0.98-1.04)$ & 0.62 \\
Hemoglobin & $0.97(0.92-1.03)$ & 0.29 \\
CRP & $1.10(0.98-1.03)$ & 0.53 \\
\hline
\end{tabular}

${ }^{\mathrm{a}} \mathrm{G} 1$ : growth impairment, as defined by treating physician following the Paris classification.?

Consequently, the use of therapeutic drug monitoring in IBD patients on IFX has been gaining interest, with more utilization in clinical practice with emerging evidence suggesting better disease outcomes with a treat-to-target approach. ${ }^{14,22,23} \mathrm{~A}$ systematic review that included 14 studies and examined the utility of TDM in children with IBD on anti-TNF agents concluded that TDM had a potential benefit and that incorporating measurements of infliximab trough levels at week 8 or week 14 predicted therapeutic responses and allowed for dose adjustments to reach therapeutic drug concentrations. However, a clinically relevant cutoff level of some anti-TNF agents has not been well defined yet, and the optimal intervention strategy still has to be determined. ${ }^{24}$ The American Gastroenterological Association (AGA) Institute guidelines suggested that the trough concentration for IFX therapy for adult patients with active luminal IBD on maintenance therapy should be $\geq 5 \mathrm{mg} / \mathrm{mL}{ }^{14}$
Established optimal trough drug concentrations for IBD subtype, disease extent, disease severity, or complicated CD have not been defined. Hence, several serum drug levels taking into account these disease phenotypes have been proposed. ${ }^{25}$. ${ }^{26}$ Moreover, it is not clear if tissue drug levels correlate with serum levels or not. ${ }^{27}$

In our cohort, the distribution of concomitant immunosuppression was similar among those with healing/healed fistulizing perianal $\mathrm{CD}$ and those who had ongoing active disease at week 24. Adult studies examining the association between concomitant immunosuppressant use and fistula closure have yielded inconsistent results. ${ }^{28,}{ }^{29}$ Nonetheless, other investigators, concordant with our results, did not show the same effect of concomitant immunosuppressants. ${ }^{11,}{ }^{16}$ Other factors that were associated with a better outcome included duration of seton drainage less than 34 weeks, longer duration of IFX treatment, ${ }^{29}$ fewer fistulas, and less active luminal disease. ${ }^{11}$

Our study is the first pediatric study exploring serum IFX levels associated with healing of fistulizing PCD in children with Crohn's disease. In addition, this is the first prospective study examining the association of serum IFX with healing of fistulizing PCD. Our study's limitations include the small number of patients with available IFX levels and incomplete characterization of the anatomy of perianal fistulas. Nonetheless, seton placement after surgical drainage was similar among those with healing/healed fistulizing perianal $\mathrm{CD}$ and those who had ongoing active disease at week 24 . The small sample size did not allow us to separate those with healing and healed fistulas. Moreover, it was not possible to explore factors affecting long-term outcome due to short duration of follow-up. Unfortunately, IFX antibodies were not available in our cohort given the use of the ELISA methodology for measuring trough levels of IFX. However, our study is novel and provides strong

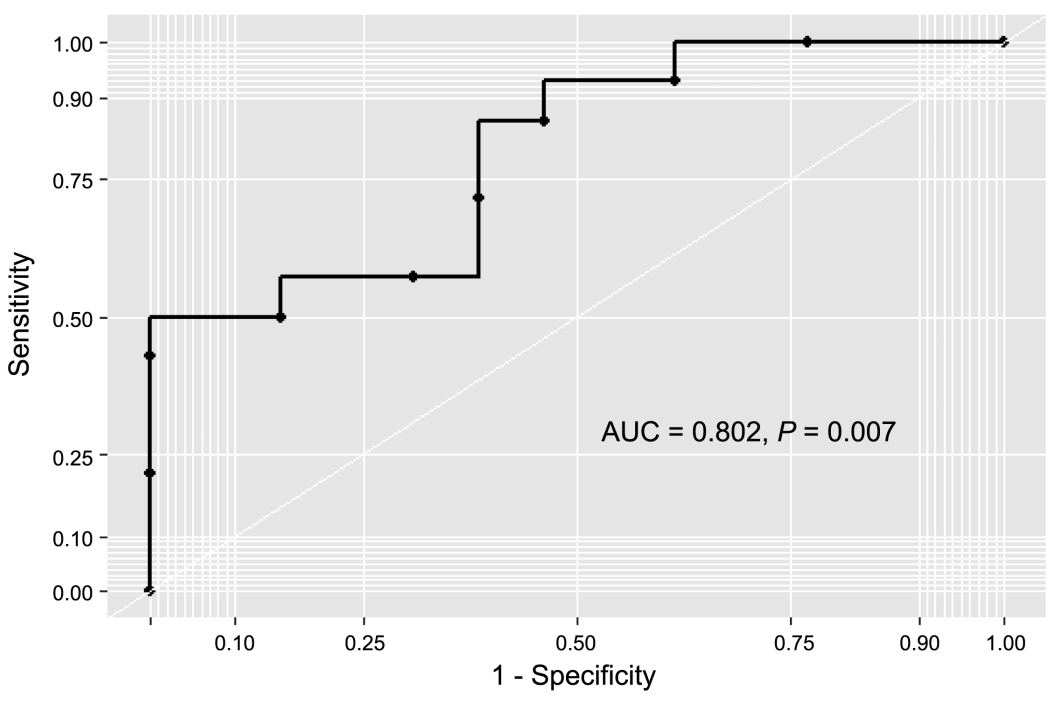

FIGURE 2. Serum IFX pre-fourth dose trough levels for prediction of fistula response at week 24. 
evidence for higher IFX dosing in children with PCD who are not healing and have lower IFX trough levels.

In conclusion, following the induction phase, higher trough IFX levels are associated with a better outcome for fistulizing PCD in children. Our results suggest that improved success in the healing of perianal $C D$ can be achieved with increased drug exposure, but they need to be confirmed in larger prospective studies.

\section{REFERENCES}

1. de Zoeten EF, Pasternak BA, Mattei P, et al. Diagnosis and treatment of perianal Crohn disease: NASPGHAN clinical report and consensus statement. J Pediatr Gastroenterol Nutr. 2013;57:401-412.

2. Keljo DJ, Markowitz J, Langton C, et al. Course and treatment of perianal disease in children newly diagnosed with Crohn's disease. Inflamm Bowel Dis. 2009; 15:383-387.

3. Palder SB, Shandling B, Bilik R, et al. Perianal complications of pediatric Crohn's disease. J Pediatr Surg. 1991;26:513-515.

4. Eglinton TW, Roberts R, Pearson J, et al. Clinical and genetic risk factors for perianal Crohn's disease in a population-based cohort. Am J Gastroenterol. 2012;107:589-596.

5. Levine A, Griffiths A, Markowitz J, et al. Pediatric modification of the Montreal classification for inflammatory bowel disease: the Paris classification. Inflamm Bowel Dis. 2011;17:1314-1321.

6. Herman Y, Rinawi F, Rothschild B, et al. The characteristics and long-term outcomes of pediatric Crohn's disease patients with perianal disease. Inflamm Bowel Dis. 2017;23:1659-1665.

7. Wise PE, Schwartz DA. The evaluation and treatment of Crohn perianal fistulae: EUA, EUS, MRI, and other imaging modalities. Gastroenterol Clin North Am. 2012;41:379-391.

8. Simpson JA, Banerjea A, Scholefield JH. Management of anal fistula. BMJ. 2012;345:e6705.

9. Crandall W, Hyams J, Kugathasan S, et al. Infliximab therapy in children with concurrent perianal Crohn disease: observations from REACH. J Pediatr Gastroenterol Nutr. 2009;49:183-190.

10. Ruemmele FM, Lachaux A, Cézard JP, et al; Groupe Francophone d'Hépatologie, Gastroentérologie et Nutrition Pédiatrique. Efficacy of infliximab in pediatric Crohn's disease: a randomized multicenter open-label trial comparing scheduled to on demand maintenance therapy. Inflamm Bowel Dis. 2009;15:388-394.

11. Dupont-Lucas C, Dabadie A, Alberti C, et al; GETAID (Group d'Etude Thérapeutique des Affections Inflammatoires du Tube Digestif) Pédiatrique. Predictors of response to infliximab in paediatric perianal Crohn's disease. Aliment Pharmacol Ther. 2014;40:917-929.

12. Present DH. Review article: the efficacy of infliximab in Crohn's disease-healing of fistulae. Aliment Pharmacol Ther. 1999;13(Suppl 4):23-28; discussion 38.
13. Sands BE, Anderson FH, Bernstein $\mathrm{CN}$, et al. Infliximab maintenance therapy for fistulizing Crohn's disease. $N$ Engl J Med. 2004;350:876-885.

14. Feuerstein JD, Nguyen GC, Kupfer SS, et al; American Gastroenterological Association Institute Clinical Guidelines Committee. American Gastroenterological Association Institute guideline on therapeutic drug monitoring in inflammatory bowel disease. Gastroenterology. 2017;153:827-834.

15. Yarur AJ, Kanagala V, Stein DJ, et al. Higher infliximab trough levels are associated with perianal fistula healing in patients with Crohn's disease. Aliment Pharmacol Ther. 2017:45:933-940.

16. Davidov Y, Ungar B, Bar-Yoseph H, et al. Association of induction inflix imab levels with clinical response in perianal Crohn's disease. J Crohns Colitis. 2017;11:549-555.

17. Papamichael K, Casteele NV, Ferrante M, et al. Therapeutic drug monitoring during induction of anti-tumor necrosis factor therapy in inflammatory bowel disease: defining a therapeutic drug window. Inflamm Bowel Dis. 2017;23:1510-1515.

18. Present DH, Rutgeerts $\mathrm{P}$, Targan S, et al. Infliximab for the treatment of fistulas in patients with Crohn's disease. $N$ Engl J Med. 1999;340:1398-1405.

19. Maser EA, Villela R, Silverberg MS, et al. Association of trough serum infliximab to clinical outcome after scheduled maintenance treatment for Crohn's disease. Clin Gastroenterol Hepatol. 2006;4:1248-1254.

20. Ungar B, Levy I, Yavne Y, et al. Optimizing anti-TNF- $\alpha$ therapy: serum levels of infliximab and adalimumab are associated with mucosal healing in patients with inflammatory bowel diseases. Clin Gastroenterol Hepatol. 2016;14:550-557.e2.

21. Chaparro M, Guerra I, Muñoz-Linares P, et al. Systematic review: antibodies and anti-TNF- $\alpha$ levels in inflammatory bowel disease. Aliment Pharmacol Ther. 2012:35:971-986.

22. Billiet T, Cleynen I, Ballet V, et al. Prognostic factors for long-term infliximab treatment in Crohn's disease patients: a 20-year single centre experience. Aliment Pharmacol Ther. 2016;44:673-683.

23. Deora V, Kozak J, El-Kalla M, et al. Therapeutic drug monitoring was helpful in guiding the decision-making process for children receiving infliximab for inflammatory bowel disease. Acta Paediatr. 2017;106:1863-1867.

24. Joosse ME, Samsom JN, van der Woude CJ, et al. The role of therapeutic drug monitoring of anti-tumor necrosis factor alpha agents in children and adolescents with inflammatory bowel disease. Inflamm Bowel Dis. 2015;21:2214-2221.

25. Baert F, Noman M, Vermeire S, et al. Influence of immunogenicity on the longterm efficacy of infliximab in Crohn's disease. N Engl J Med. 2003;348:601-608.

26. Vande Casteele N, Khanna R, Levesque BG, et al. The relationship between infliximab concentrations, antibodies to infliximab and disease activity in Crohn's disease. Gut. 2015;64:1539-1545.

27. Yarur AJ, Jain A, Sussman DA, et al. The association of tissue anti-TNF drug levels with serological and endoscopic disease activity in inflammatory bowel disease: the ATLAS study. Gut. 2016;65:249-255.

28. Dupont-Lucas C, Dabadie A, Alberti C, et al. Predictors of response to infliximab in paediatric perianal Crohn's disease. Aliment Pharmacol Ther. 2014;40:917-929.

29. Bouguen G, Siproudhis L, Gizard E, et al. Long-term outcome of perianal fistulizing Crohn's disease treated with infliximab. Clin Gastroenterol Hepatol. 2013;11:975-981.e1. 